\title{
Prescribing Better Buildings as Preventive Medicine: Using Building Design to Optimize Health and Well-Being Outcomes
}

Nichole M Campbell

Shimberg Center for Housing Studies, Rinker School of Construction Management, University of Florida, FL, USA

*Corresponding author: Nichole M. Campbell, Research Scholar, Shimberg Center for Housing Studies, Rinker School of Construction Management, University of Florida, P.O. Box 115705, Gainesville, FL32611, USA, Tel: 352-275-1199; E-mail: nmcampbell@ufl.edu

Rec date: December 07, 2017; Acc date: December 21, 2017; Pub date: December 26, 2017

Copyright: ( 2017 Campbell NM. This is an open-access article distributed under the terms of the Creative Commons Attribution License, which permits unrestricted use, distribution, and reproduction in any medium, provided the original author and source are credited.

\begin{abstract}
This study's goal was to understand how to change neighborhood environments to better support health, wellbeing, and independence for older adults seeking to remain in their family homes even if their capabilities change, commonly referred to as aging in place. To accomplish this, this study considered factors identified in prior research as relevant to supporting successful aging within mainstream neighborhoods. To improve the utility of these earlier findings, this study mathematically identified the highest priority factors among the original 40 factors by using MultiAttribute Utility Theory (MAUT), a multi-criteria decision-making method. This study connects seniors' preference for aging in place with helping designers make that an achievable and desirable option.
\end{abstract}

Keywords: Aging in place; Building design characteristics; Health and well-being; Social interaction

\section{Introduction}

Intended "to protect, promote, and maintain health and well-being and to prevent disease, disability, and death" (ACPM) [1], traditional preventive medicine uses medical interventions to stop or even prevent disease. Beyond medical research and practice, many studies demonstrate health and wellness benefits may be gained through other, non-medical interventions. In particular, this paper seeks to introduce the area of research called Environment and Behavior Studies (EBS) which is the study of the influence the built environment has on human health and well-being. To illustrate its application, this paper reports on a recent study examining neighborhood and building design characteristics that support improved older adult health, wellbeing, and independence.

\section{Literature Review}

\section{Non-medical interventions influencing health and well-being}

Originating in the 1960s, Environment and Behavior research seeks to understand the interaction between people and the designed environment [2]. Within that body of literature, lie many examples of non-medical interventions influencing human health and well-being. As the EBS field is only decades rather than centuries old, it may be unfamiliar to individuals outside of this field. Despite its unfamiliarity, this body of research consistently indicates environments influence the people who use them, either positively or negatively. With that, the ways buildings influence human health and well-being include supporting basic physiological needs as well as the ability to meet complex, higher-order needs like social engagement [3].

\section{Surroundings most impact the very old and ill}

From the collective EBS body of research, we know building design can impact health and well-being in many ways for any aged individual. With that, seminal research in this field indicated the impact of the designed environment is greatest on older adults and individuals with marginalized health [4]. In other words, the very old and sick are impacted most by their surroundings.

Despite this, over $90 \%$ of older adults seek age in place [5] even if their health or capabilities decline. Aging in place means "not having to move from one's present residence in order to secure necessary support services in response to changing needs" [6]. For older adults to achieve the goal of living late life in their family homes, one area EBS research encompasses is home and neighborhood design to support common changes and disabilities associated with advanced age.

In 1990, a U.S. civil rights law, the Americans for Disability Act (ADA), addressing needs of individuals with disabilities was established. This led to ADA building design requirements. Applying to public buildings, these design criteria are intended to create buildings that are accessible and usable for people with disabilities. Even though the ADA guidelines do not apply to private residences, still it is necessary to support varying physiological needs in home environments in order for disabled and/or older adults to safely maneuver and live in their homes. Without the capability to perform activities of daily living and meet other basic needs, individuals will be unable to continue living independently.

\section{Beyond solutions for sustaining life}

While meeting basic human needs is critical to sustaining life and independence, higher level needs- such as social needs- must be addressed to provide life quality. In recent years, EBS aging-in-place research expanded to address human needs in the built environment more holistically. In the context of meeting senior needs for aging in place, Wiles, Leibing, Guberman, Reeve, and Allen [7] provided support for the assertion that social connection was a critical component of life quality. In that study, Wiles et al. found it was the social connections with neighbors and local friends that prompted older adults to steadfastly insist on remaining in their current homes in later life. This evidence suggests the value for seniors aging in place lies 
in the ability to maintain social connections. From a design standpoint, there is a need optimally design neighborhoods and neighborhood gathering places to support these social relationships.

Numerous studies show“...a strong correlation between social interaction and health and well-being among older adults" [8]. This in addition to the awareness of the need for senior-friendly housing has spurred dialog on a large scale concerning how to optimally support seniors' social lives. For instance, the World Health Organization (WHO) established providing senior housing supporting daily social interaction one of their active aging initiative goals [9]. As the evidence for promoting interaction in late life accumulates, there is an increasing need to understand factors influencing social interaction's quality and frequency. With this, the question remaining to be answered in EBS research is:

How can mainstream neighborhood design more successfully meet seniors' social needs?

\section{Discussion}

Since the vast majority of seniors prefer aging at home, it is advantageous to understand how to create environments fostering physical and social interaction needs in order to promote better health and well-being outcomes, ultimately supporting senior life quality and independence. This study sought to reveal the relative importance of neighborhood-scale and commercial gathering space (i.e. restaurants or shops) attributes identified in prior research as aiding aging-inplace seniors.

To accomplish this, insights were gathered from 63 seniors living within the case study neighborhood community. Data were gathered via interviews structured for Multi Attribute Utility Theory (MAUT) analysis. MAUT analysis provides mathematical insight into each factor's relative value which is useful for pinpointing design priorities. When comparing options with strengths and weaknesses, by design this method accounts for these tradeoffs in order to help make optimal decisions [10]. This method is highly suitable in EBS research because rather than only indicating what factors are important, it quantifies how important each factor is compared to others. In other words, it can inform developers, architects, and designers about which characteristics are the most essential to include in a neighborhood or building's design in order for the designed environment to function in the ways these spaces were intended.

In an earlier study, 20 neighborhood-scale factors as well as 20 building-level factors were identified as attracting and supporting older adults seeking to age in place in traditional neighborhoods. The identified factors included characteristics of the overall neighborhood design as well as the characteristics of individual commercial gathering places within the neighborhood. Due to budget and time constraints, often it is not practical to include all evidence-based recommendations in every design scenario. Since the former study generated 40 recommended factors, this study identified which key factors among those should be prioritized most highly. This gave greater utility to the former study's findings.

Based on the MAUT analysis data findings, the characteristics that should be prioritized highest in the neighborhood's overall design included:

- Conveniently locating key retail venues: In a neighborhood development, clustering key retail venues (i.e. pharmacy, grocery, etc.) near residences and even combining commercial functions (i.e. providing a drug store combined with a coffee shop) help older adults meet social needs. The reason those strategies are helpful is because diminishing physiological capabilities make it more challenging and energy-intensive to make trips beyond the home which in turn tends to limit the number and frequency of trips outside the home individuals may make. By clustering venues or including multiple functions in a single structure, these design strategies enable seniors to accomplish more using less time and energy.

- Maintaining the site's natural beauty: To simplify the construction process, building sites are commonly clearcut, meaning all trees and vegetation are cleared from the site before construction begins. One downside of this practice is it limits the integration of nature into new neighborhoods since it takes decades to reestablish stately trees and densely wooded areas on a clear-cut site. Not only does the mature vegetation visually appeal to older residents, EBS research consistently indicates engagement with nature has a restorative effect on health. For example, one study with over 1,200 participants found people of all-ages experienced improved selfesteem and mood related to engagement with nature [11].

On a building-level scale, this study's data indicated essential factors to include in designing neighborhood gathering places included:

- Creating spaces supportive of private conversation and group gatherings: One advantage of creating flexible spaces that support private conversations as well as group gatherings is this strategy allows patrons to choose how much social interaction they want or need to engage in at a given moment. To provide this, designers must include various-sized seating alcoves so visitors may have options to suit their interaction needs.

- Appealing to mixed ages: In a neighborhood housing individual of all ages, neighborhood commercial venues often to try to maximize the number of potential customers by appealing to a diverse age range. For a commercial venue to appeal to mixed ages, the first step is to design the facility universally so the space functions well for people of varying age and ability levels. For example, to make facilities more usable and appealing to individuals with hearing impairments, care should be taken to design spaces with well-controlled acoustics by lowering ceiling heights, using sound-absorbent finishes, and provide alcoves where seating is protected from background noise. Being proactive with design strategies enables a wider variety of people to patronize the venue.

\section{Conclusion}

This paper sought to introduce the area of research called environment and behavior studies which examines the influence the designed environment has on human health and well-being. To illustrate the application of research in this field, this paper reported findings from a recent study exploring neighborhood and building design factors supporting improved health, well-being, and independence for older adults. More specifically, this study mathematically identified the highest priority factors among 40 factors relevant to supporting successful aging within mainstream neighborhoods.

In the design and building industry, these findings will help guide neighborhood and gathering space design to create optimal value for seniors. This, in turn, will support seniors' physiological and social needs. By imbibing mainstream communities with attributes attractive 
Citation: Campbell NM (2017) Prescribing Better Buildings as Preventive Medicine: Using Building Design to Optimize Health and Well-Being Outcomes. J Gerontol Geriatr Res 6: 456. doi:10.4172/2167-7182.1000456

Page 3 of 3

and supportive to seniors, this may enable seniors to maintain independence and life quality longer. This study bridges seniors' preference for aging in place with helping designers make that a feasible and desirable option. Also, this study's insights may provide further evidence of how to use the built environment as another layer of support for optimizing health, well-being and independence throughout the lifespan.

\section{References}

1. http://www.acpm.org/page/preventivemedicine.

2. http://www.edra.org/page/missionvaluehistory.html.

3. Hunt ME (1992) The design of supportive environments for older people. J Hous Elderly 9: 127-140.

4. Lawton MP (1974) Social ecology and the health of older people. Am J Public Health 64: 257-260.

5. Oswald F, Jopp D, Rott C, Wahl HW (2011) Is aging in place a resource for or risk to life satisfaction? Gerontologist 51: 238-250.
6. Pastalan L (1990) Aging in place: The role of housing and social supports. Haworth Press. Binghamton, NY, USA.

7. Wiles J, Leibing A, Guberman N, Reeve J, Allen R (2012) The meaning of "aging in place" to older people. Gerontologist 52: 357-366.

8. National Institute on Aging (2017) Research suggests a positive correlation between social interaction and health. NIA.NIH.gov. Retrieved from https://www.nia.nih.gov/about/living-long-well-21stcentury-strategic-directions-research-aging/research-suggests-positive.

9. World Health Organization (WHO) (2002) Active ageing: A policy framework. A contribution of the World Health Organization to the Second United Nations World Assembly on Ageing. Madrid, Spain.

10. Velasquez M, Hester P (2013) An analysis of multi-criteria decision making methods. Int J Oper Res 10: 56-66.

11. Barton J, Pretty J (2010) What is the best dose of nature and exercise for improving health? A multi-study analysis. Environ Sci Technol 44: 3947-3955. 